БИТЮЦКАЯ Е. В., ЛЕБЕДЕВА Н. А., ЦАЛИКОВА Ю. Р.

ИЗМЕНЕНИЕ ОБЪЕМА КРАТКОВРЕМЕННОЙ ПАМЯТИ ПОД ВЛИЯНИЕМ СТРЕССОГЕННОГО ВОЗДЕЙСТВИЯ У КУРСАНТОВ

РосСИЙСКИЙ пСИХОЛОГИЧЕСКИЙ ЖУРнАл, 2020, Т. 17, № 1, 27-43. doi: 10.21702/rpj.2020.1.3

ОБЩАЯ ПСИХОЛОГИЯ, ПСИХОЛОГИЯ лИЧНОстИ, ИСТОРИЯ ПСИХОЛОГИИ

УдK 159.953.3 doi: $10.21702 /$ rpj.2020.1.3

Оригинальная научная статья

\title{
Изменение объема кратковременной памяти под влиянием стрессогенного воздействия у курсантов
}

\author{
Екатерина В. Битюцкая', Наталья А. Лебедева2 ${ }^{\star}$, Юлия Р. Цаликова ${ }^{1}$ \\ ${ }^{1}$ Московский государственный университет имени М. В. Ломоносова, г. Москва, Российская Федерация \\ 2 Московский городской университет управления Правительства Москвы, г. Москва, Российская \\ Федерация \\ *E-mail: nattalea@mail.ru \\ ORCID ID: https://orcid.org/0000-0001-6117-1063, https://orcid.org/0000-0001-8727-8774, \\ https://orcid.org/0000-0002-0778-1749
}

\begin{abstract}
Аннотация
Введение. Исследуется влияние стрессогенного возАействия Умеренной интенсивности на кратковременную память, что востребовано практикой поАготовки специалистов экстремального профриля (спасателей) к профрессиональной Аеятельности. Объектом исслеАования является изменение объема кратковременной памяти поА возАействием стрессогенных фракторов. Опрелелено существование значимых различий межАу показателями памяти курсантов и студентов специальностей, не связанных с Аеятельностью в экстремальных условиях. Новизна заключается в проведенном экспериментальном исслеАовании влияния стрессогенного возАействия на объем кратковременной памяти с учётом фрактора профрессиональной направленности испытуемых.
\end{abstract}

Метолы. В исслеАовании приняли участие 90 человек: 50 курсантов силового веАомства и 40 студентов московских вузов. Испытуемые были разделены на четыре группы, из которых олна экспериментальная и три контрольные. Авум группам были преАьявлены фоото- и аудиоматериалы стрессогенного солержания; Авум Аругим группам - материалы нейтрального солержания. Объем кратковременной памяти испытуемых Ао и после предьявления материалов определя^ся при помощи метолики Digit Span Test. Ha протяжении всего эксперимента замерялись фризиологические параметры испытуемых.

Результаты. У курсантов силового веАомства объем памяти в стрессогенных условиях значимо увеличивается, в то время как объем памяти студентов показывает незначимое снижение. Также в стрессогенных условиях стуленты и курсанты Аемонстрируют разный фризиологический ответ: студенты имеют более высокое исходное мышечное напряжение, в то время как показатели сердечно-сосудистой системы курсантов (амплитуда систолической волны, время распространения пульсовой волны) меняются быстрее, при этом не так выраженно, как У стуАентов.

Обсужаение результатов. Показатели объема памяти и его устойчивость к стрессогенным возАействиям курсантов связаны с уровнем невербального интел^екта, а также могут быть опосреАованы профрессионально-важными качествами и мотивационными особенностями. В качестве важного фрактора устойчивости когнитивных функций рассматривается система отбора и психологического сопровожАения курсантов силового веАомства. 
БИТЮЦКАЯ Е. В., ЛЕБЕДЕВА Н. А., ЦАЛИКОВА Ю. Р.

ИЗМЕНЕНИЕ ОБЪЕМА КРАТКОВРЕМЕННОЙ ПАМЯТИ ПОД ВЛИЯНИЕМ СТРЕССОГЕННОГО ВОЗДЕЙСТВИЯ У КУРСАНТОВ

Российский психологИчЕский жУРнАл, 2020, Т. 17, № 1, 27-43. doi: 10.21702/rpj.2020.1.3

ОБЩАЯ ПСИХОЛОГИЯ, ПСИХОЛОГИЯ ЛИЧНОСтИ, ИСТОРИЯ ПСИхОЛОГИИ

\section{КАючевые слова}

кратковременная память, объем памяти, стрессогенное воздействие, Digit Span Test, цель, когнитивное оценивание, интенсивность стрессора, саморегуляция, эмоциональное напряжение (arousal), фризиологические параметры

\section{Основные положения}

จ поА возАействием стрессогенных стимулов объем кратковременной памяти увеличивается у большинства курсантов, чья будущая профрессиональная Аеятельность связана с преоАо^ением экстремальных ситуаций;

> увеличение объема кратковременной памяти рассмотрено как показатель эдроективности специалистов экстремального профиля при возАействии стрессоров;

> результаты обсужАаются в связи с профрессионально важными качествами специалистов экстремального профиия (Оптимистичностью, позитивной оценкой своих си^ и возможностей, энергичностью), а также системой обучения курсантов, позволяющей сохранять самооблаАание и устойчивость при выполнении профрессиональных заАач в сложных условиях.

\section{Для цитирования}

Битюцкая, Е. В., Лебедева, Н. А. и Цаликова, Ю. Р. (2020). Изменение объема кратковременной памяти под влиянием стрессогенного воздействия у курсантов. Российский психологический журнал, 17(1), 27-43. doi: 10.21702/rpj.2020.1.3

Дата получения рукописи: 30.01 .2020

Дата окончания рецензирования: 05.03.2020

Дата принятия к публикации: 09.03.2020

\section{Введение}

Специфика профессиональной деятельности специалистов экстремальных профессий определяется необходимостью действовать в условиях воздействия стрессоров экстремальной интенсивности, связанных с ликвидацией последствий чрезвычайных ситуаций и стихийных бедствий. При этом спасателям, пожарным важно сохранять адекватную оценку ситуации, целенаправленность деятельности, что связано с устойчивостью когнитивных функций. Изучение особенностей функционирования познавательных процессов под воздействием стрессоров актуальная тема, поскольку востребована практикой подготовки курсантов к деятельности в экстремальных ситуациях.

В ряде исследований показано, что функционирование кратковременной (рабочей) памяти связано с распределением ресурсов, контролем внимания и поведения и в целом определяет эффективность решения сложных задач (Barrett, Tugade, \& Engle, 2004). Соответственно, кратковременная память может рассматриваться как важный компонент эффективности спасателей в экстремальных условиях.

В современной психологии описаны многочисленные факты как улучшения, так и ухудшения когнитивной активности под влиянием стресса. Целью данной работы является изучение особенностей функционирования памяти у курсантов, чья будущая профессиональная деятельность связана с работой в условиях чрезвычайных ситуаций. Поэтому особый интерес для нас представляет анализ факторов и механизмов, которые объясняют эффективность 
БИТЮЦКАЯ Е. В., ЛЕБЕДЕВА Н. А., ЦАЛИКОВА Ю. Р.

ИЗМЕНЕНИЕ ОБЪЕМА КРАТКОВРЕМЕННОЙ ПАМЯТИ ПОД ВЛИЯНИЕМ СТРЕССОГЕННОГО ВОЗДЕЙСТВИЯ У КУРСАНТОВ

РосСИЙСКИЙ пСИХОЛОГИЧЕСКИЙ ЖУРнАл, 2020, Т. 17, № 1, 27-43. doi: 10.21702/rpj.2020.1.3

ОБЩАЯ ПСИХОЛОГИЯ, ПСИХОЛОГИЯ ЛИЧНОСТИ, ИСТОРИЯ ПСИХОЛОГИИ

выполнения задачи под воздействием стрессора. В этом контексте рассмотрим исследования когнитивного оценивания стресса, интенсивности стрессора и саморегуляции.

\section{Когнитивное оценивание стресса как фактор активности}

В ряде работ показано, что активное преодоление стрессовых ситуаций лучше предсказывает оценка «вызов» (Lazarus, 1991). Она определяется восприятием стрессовой ситуации как возможности улучшить свои навыки и знания, стать более сильным и т. п. Для возникновения этой оценки важна уверенность человека в том, что его ресурсов достаточно для достижения успеха (Tomaka, Blascovich, Kelsey, \& Leitten, 1993). В свою очередь, оценка «вызов» активизирует человека на преодоление и отрицательно связана с избеганием (Blascovich \& Tomaka, 1996; Tomaka et al., 1993).

В недавнем метаобзоре показано, что оценка «вызов» связана с улучшением продуктивности деятельности в напряженных условиях (Hase, O'Brien, Moore, \& Freeman, 2019). Так, хирурги, у которых преобладала эта оценка, лучше проводили операцию, демонстрировали более высокие моторные навыки и показатели внимания (Vine, Freeman, Moore, ChandraRamanan, \& Wilson, 2013). Летчики с преобладанием оценки «вызов» при отработке сценария отказа двигателя были способны эффективно использовать актуальную информацию и более безопасно приземляться (Vine et al., 2015).

В ряде исследований проверялись гипотезы о связи оценки стрессовой ситуации и физиологических показателей. В частности, показано, что позитивное отношение к стрессу, при котором он воспринимается как мобилизация возможностей, связано с умеренной кортизоловой активацией (Crum, Salovey, \& Achor, 2013). В другом исследовании студентам экспериментальной группы во время подготовки к экзамену приводили доводы в пользу того, что состояние стресса улучшает эффективность работы. По результатам исследования были сделаны выводы, что положительное отношение к стрессу, сформированное в экспериментальной группе, определяло, с одной стороны, лучшие баллы при сдаче экзаменов, с другой стороны, более высокий уровень активации симпатической системы (по сравнению с контрольной группой) (Jamieson, Mendes, Blackstock, \& Schmader, 2010).

\section{Влияние интенсивности стрессора на когнитивную активность}

Одним из активно обсуждаемых вопросов в современных исследованиях является «обратная U-образная зависимость» эмоционального напряжения / возбуждения (arousal) и когнитивных процессов, впервые представленная в работе Easterbrook (1959). U-образная зависимость описывает более высокую эффективность внимания и памяти при умеренном стрессе. В более поздних исследованиях это было конкретизировано: средний уровень эмоционального напряжения может улучшать запоминание и воспроизведение информации, особенно эмоционально заряженной (McGaugh, 2006; Cahill, Gorski, \& Le, 2003; Buchanan \& Lovallo, 2001). Также на низком и среднем уровнях напряжения улучшаются показатели скорости выполнения когнитивных заданий (Hancock \& Weaver, 2005). По мере того, как уровень возбуждения растет, память на детали события ухудшается за счет сужения внимания при запоминании (Buchanan, Tranel, \& Adolphs, 2006; Sharot \& Phelps, 2004).

Исследования U-образной зависимости связаны, в частности, с рассмотрением факторов, которые ее опосредуют. Например, выявляются разные закономерности для положительных и отрицательных эмоций одинаковой интенсивности. Это является аргументом в пользу того, 
БИТЮЦКАЯ Е. В., ЛЕБЕДЕВА Н. А., ЦАЛИКОВА Ю. Р.

ИЗМЕНЕНИЕ ОБЪЕМА КРАТКОВРЕМЕННОЙ ПАМЯТИ ПОД ВЛИЯНИЕМ СТРЕССОГЕННОГО ВОЗДЕЙСТВИЯ У КУРСАНТОВ

Российский психологИчЕский жУРнАл, 2020, Т. 17, № 1, 27-43. doi: 10.21702/rpj.2020.1.3

ОБЩАЯ ПСИХОЛОГИЯ, ПСИХОЛОГИЯ ЛИЧНОСТИ, ИСТОРИЯ ПСИХОЛОГИИ

что уровень эмоционального возбуждения (arousal) сам по себе не способен полностью объяснить особенности функционирования познавательных процессов под влиянием стресca (Mather, 2007; Sharot \& Phelps, 2004; Levine \& Pizarro, 2004; Levine \& Burgess, 1997; Bargh \& Cohen, 1978). Кроме того, выявлена опосредующая роль эмоциональной регуляции. Люди, подавляющие выражение эмоций (в повседневной жизни или в результате следования инструкции в эксперименте), хуже запоминают эмоциональное содержание событий (Bonanno, Papa, Lalande, Westphal, \& Coifman, 2004).

\section{Саморегуляция и когнитивная активность}

Проблема эффективности когнитивных функций обсуждается в исследованиях саморегуляции. При этом для объяснения индивидуальных особенностей саморегуляции используется понятие функциональных состояний, которое связано с эффективностью деятельности, оптимальным достижением цели (Леонова и Кузнецова, 2015). Особое значение функциональное состояние имеет в экстремальных условиях, поскольку оказывает определяющее влияние на результаты профессиональной деятельности (Дикая, 1999). Выделяют «продуктивную напряженность» как оптимальное состояние, в отличие от стресса, который считается неблагоприятным состоянием (Дикая и Щедров, 1999).

Для настоящего исследования важен вывод о целенаправленном характере деятельности при успешном преодолении стресса (Дикая, 1999; Леонова и Кузнецова, 2015; и др.). В исследованиях Зотова (2011) показано, что при воздействии стрессогенных раздражителей произвольная регуляция деятельности сохраняется при условии целенаправленности когнитивной активности. Бодров и Обознов (2000) к факторам стрессоустойчивости относят образ-прогноз достижения результатов, предвосхищающие схемы, что также связано с целеполаганием. На материале эмпирических данных С. А. Шапкин показывает, что при достижении значимых для человека целей, связанных с высокими результатами (стратегия достижения), даже при дефиците ресурсов, происходит не только достижение цели, но и сохранение благоприятного психического состояния. Напротив, если задачей становится экономия ресурсов (стратегия избегания), это приводит как к неуспеху в достижении целей, так и к истощению ресурсов, а также к ухудшению психического состояния (Шапкин, 1999).

В целом, при хорошей разработанности проблемы влияния стрессовых воздействий на функционирование познавательной сферы, можно отметить недостаток исследований на выборках профессионалов и будущих специалистов, чья деятельность связана со стрессорами экстремальной интенсивности. Мы предполагаем, что под воздействием стрессогенных факторов у спасателей достигается оптимальное функциональное состояние (в терминах Л. Г. Дикой и В. И. Щедрова - продуктивная напряженность). Одним из проявлений такого продуктивного состояния может быть устойчивый к воздействию стресса объем памяти. Это связано - на мотивационном уровне - с целенаправленностью действий при выполнении профессиональных задач. В более широком контексте важно указать на систему отбора и психологической подготовки курсантов в ведомственных вузах МЧС. Данное общее предположение конкретизируется в следующей гипотезе настоящего исследования: у курсантов, чья профессиональная деятельность будет связана с экстремальным профилем, в условиях стрессогенного воздействия объем кратковременной памяти увеличивается. 
БИТЮЦКАЯ Е. В., ЛЕБЕДЕВА Н. А., ЦАЛИКОВА Ю. Р.

ИЗМЕНЕНИЕ ОБЪЕМА КРАТКОВРЕМЕННОЙ ПАМЯТИ ПОД ВЛИЯНИЕМ СТРЕССОГЕННОГО ВОЗДЕЙСТВИЯ У КУРСАНТОВ

РосСИЙСКИЙ пСИХОЛОГИЧЕСКИЙ ЖУРнАл, 2020, Т. 17, № 1, 27-43. doi: 10.21702/rpj.2020.1.3

ОБЩАЯ ПСИХОЛОГИЯ, ПСИХОЛОГИЯ ЛИЧНОСТИ, ИСТОРИЯ ПСИХОЛОГИИ

\section{Методы}

\section{Участники исследования}

Всего в исследовании приняли участие 97 человек. Результаты 7-ми человек (3-х курсантов и 4-х студентов) были исключены из материала для анализа настоящей работы. Таким образом, представленные результаты и выводы делались на основе исследования общей выборкой 90 человек: из них 50 московских курсантов силового ведомства (МЧС России) и 40 студентов московских вузов (МГУ имени М. В. Ломоносова, Всероссийская академия внешней торговли, Московский государственный юридический университет имени О. Е. Кутафина), обучающихся по специальностям: география, геология, экономика, юриспруденция и др. Экспериментальная группа состояла из 30-ти курсантов: 15 мужчин, 15 женщин в возрасте от 21 до 24 лет. Остальные участники вошли в 3 группы сравнения. Подробно возрастные и половые характеристики всех участников исследования указаны в таблице 1.

\section{Процедура проведения исследования}

Для проведения исследования за основу был взят план для четырех рандомизированных групп с предварительным и итоговым тестированием. Экспериментальный план представлен в таблице 1.

\begin{tabular}{|c|c|c|c|c|}
\hline $\begin{array}{l}\text { Группа } \\
\text { курсантов }\end{array}$ & \multirow{5}{*}{$\begin{array}{l}\text { Предварительное } \\
\text { тестирование } \\
\text { кратковременной } \\
\text { памяти (1-я серия } \\
\text { предьявлений } \\
\text { Digit Span Test) }\end{array}$} & $\begin{array}{l}\text { Стрессогенное } \\
\text { возАействие }\end{array}$ & $\begin{array}{l}\text { Группа 1, } 30 \text { человек: } \\
15 \text { мужчин, } \\
15 \text { женщин } \\
\text { в возрасте от } 21 \\
\text { до } 24 \text { лет }(M=21,8)\end{array}$ & \multirow{5}{*}{$\begin{array}{l}\text { Итоговое } \\
\text { тестирование } \\
\text { кратковременной } \\
\text { памяти (2-я серия } \\
\text { предьявений } \\
\text { Digit Span Test) }\end{array}$} \\
\hline $\begin{array}{l}\text { МЧС России } \\
\text { (50 человек) }\end{array}$ & & Нет & $\begin{array}{l}\text { Группа 2, } 20 \text { человек: } \\
10 \text { мужчин, }\end{array}$ & \\
\hline & & $\begin{array}{l}\text { стрессогенного } \\
\text { возАействия }\end{array}$ & $\begin{array}{l}10 \text { женщин } \\
\text { в возрасте от } 22 \\
\text { Ао } 24 \text { ^ет }(\mathrm{M}=21,5)\end{array}$ & \\
\hline $\begin{array}{l}\text { Группа } \\
\text { студентов }\end{array}$ & & $\begin{array}{l}\text { Стрессогенное } \\
\text { воздействие }\end{array}$ & $\begin{array}{l}\text { Группа 3, } 20 \text { человек: } \\
10 \text { мужчин, } \\
10 \text { женщин } \\
\text { в возрасте от } 19 \\
\text { до } 24 \text { лет }(M=21,3)\end{array}$ & \\
\hline $\begin{array}{l}\text { гражАанских } \\
\text { вузов } \\
\text { (40 человек) }\end{array}$ & & $\begin{array}{l}\text { Нет } \\
\text { стрессогенного } \\
\text { воздействия }\end{array}$ & $\begin{array}{l}\text { Группа 4, } 20 \text { человек: } \\
10 \text { мужчин, } \\
10 \text { женщин } \\
\text { в возрасте от } 20 \\
\text { до } 23 \text { лет }(\mathrm{M}=21,6)\end{array}$ & \\
\hline
\end{tabular}

Участникам групп, которые выполняли задания в условиях стрессогенного воздействия, предъявлялись фото- и аудиоматериалы стрессогенного содержания. Фотоматериалы содержали снимки с мест во время чрезвычайных ситуаций, тела погибших и пострадавших, пожары, 
БИТЮЦКАЯ Е. В., ЛЕБЕДЕВА Н. А., ЦАЛИКОВА Ю. Р.

ИЗМЕНЕНИЕ ОБЪЕМА КРАТКОВРЕМЕННОЙ ПАМЯТИ ПОД ВЛИЯНИЕМ СТРЕССОГЕННОГО ВОЗДЕЙСТВИЯ У КУРСАНТОВ

Российский психологИчЕский жУРнАл, 2020, Т. 17, № 1, 27-43. doi: 10.21702/rpj.2020.1.3

ОБЩАЯ ПСИХОЛОГИЯ, ПСИхОЛОГИЯ ЛИЧНОСтИ, ИСТОРИЯ ПСИхОЛОГИИ

разрушенные в результате землетрясений здания. Помимо фотографий данной категории, демонстрировались изображения опасных насекомых, крови, медицинских игл и шприцов. Аудиоматериалы стрессогенного содержания включали в себя записи криков людей, звуков сирен, лая собак, плача детей.

Фотоматериалы стрессогенного содержания демонстрировались на протяжении 2-х минут перед итоговым тестированием памяти; параллельно в наушники испытуемому подавались звуки. Во время итогового тестирования звуки продолжали подаваться в наушники (табл. 2).

Кроме того, испытуемым демонстрировалось видео нейтрального содержания с изображением природы: на первом этапе исследования (в течение одной минуты) - для измерения физиологических параметров в исходном спокойном состоянии; на третьем и завершающем этапах исследования (также в течение одной минуты) схожие по содержанию видеоматериалы использовались для отдыха (табл. 2).

Все испытуемые были предупреждены о том, что они будут принимать участие в исследовании, направленном на изучение памяти, и о наличии материала стрессогенного содержания. Кроме того, сообщалось о возможности отказаться от участия в исследовании в любой момент проведения эксперимента: в случае, если станет неприятно или некомфортно. Также участникам эксперимента сообщали об использовании данных в обобщенном виде. В процессе проведения исследования отказов от участия не было.

\begin{tabular}{|c|c|c|c|c|c|}
\hline \multicolumn{6}{|c|}{$\begin{array}{l}\text { Таблица } 2 \\
\text { Процедура проведения исследования }\end{array}$} \\
\hline $\begin{array}{c}\frac{\text { Этапы }}{\text { исслеА- }} \\
\underline{\text { ования }}\end{array}$ & \multicolumn{2}{|c|}{$\frac{\text { Группы без стрессогенного }}{\underline{\text { возАействия }}}$} & \multicolumn{3}{|c|}{ Группы со стрессогенным возАействием } \\
\hline 1 & $\begin{array}{l}\text { ВиАео } \\
\text { нейтрального } \\
\text { содержания }\end{array}$ & $\begin{array}{l}\text { Замер фризио- } \\
\text { ^огических } \\
\text { параметров }\end{array}$ & $\begin{array}{l}\text { Вилео } \\
\text { нейтрального } \\
\text { солержания }\end{array}$ & \multicolumn{2}{|c|}{$\begin{array}{l}\text { Замер } \\
\text { фризиологических } \\
\text { параметров }\end{array}$} \\
\hline 2 & Digit Span Test & $\begin{array}{l}\text { Замер фризио- } \\
\text { ^огических } \\
\text { параметров }\end{array}$ & Digit Span Test & $\begin{array}{l}\text { Зам } \\
\text { ориз } \\
\text { пар }\end{array}$ & омогических \\
\hline 3 & \multicolumn{2}{|c|}{ Вилео нейтрального солержания } & \multicolumn{3}{|c|}{ Вилео нейтрального солержания } \\
\hline 4 & \multicolumn{2}{|c|}{-} & \multicolumn{3}{|c|}{$\begin{array}{l}\text { Фото- и аудиоматериалы стрессогенного } \\
\text { содержания }\end{array}$} \\
\hline 5 & $\begin{array}{l}\text { Digit Span } \\
\text { Test }\end{array}$ & $\begin{array}{l}\text { иер } \\
\text { зиологических } \\
\text { ометров }\end{array}$ & $\begin{array}{l}\text { Аудиоматериалы } \\
\text { стрессогенного } \\
\text { содержания }\end{array}$ & $\begin{array}{l}\text { Digit } \\
\text { Span } \\
\text { Test }\end{array}$ & $\begin{array}{l}\text { Замер } \\
\text { фризиологических } \\
\text { параметров }\end{array}$ \\
\hline 6 & \multicolumn{2}{|c|}{ Вилео нейтрального солержания } & \multicolumn{3}{|c|}{ Вилео нейтрального солержания } \\
\hline
\end{tabular}


БИТЮЦКАЯ Е. В., ЛЕБЕДЕВА Н. А., ЦАЛИКОВА Ю. Р.

ИЗМЕНЕНИЕ ОБЪЕМА КРАТКОВРЕМЕННОЙ ПАМЯТИ ПОД ВЛИЯНИЕМ СТРЕССОГЕННОГО ВОЗДЕЙСТВИЯ У КУРСАНТОВ

РосСИЙСКИЙ пСИХОЛОГИЧЕСКИЙ ЖУРнАл, 2020, Т. 17, № 1, 27-43. doi: 10.21702/rpj.2020.1.3

ОБЩАЯ ПСИХОЛОГИЯ, ПСИХОЛОГИЯ ЛИЧНОСТИ, ИСТОРИЯ ПСИХОЛОГИИ

\section{Оценка состояния испытуемых с помощью физиологических параметров}

Для оценки состояния испытуемых использовалась технология биологической обратной связи (БОС «Реакор»), включающая в себя: компьютер (использовался для контроля и управления ходом исследования), монитор пациента (использовался для предъявления визуальных стимулов), блок пациента «Реакор» (состоит из четырех универсальных полиграфических каналов) и комплект датчиков для фиксации физиологических сигналов.

С помощью БОС оценивалось, находились ли испытуемые, на которых производилось воздействие стрессогенными стимулами, в состоянии физиологического напряжения (arousal), а также находились ли испытуемые, на которых не производилось воздействие стрессогенными стимулами, в нейтральном (спокойном) состоянии. Для этого на протяжении всего исследования производилась запись физиологических параметров, затем замеры физиологических показателей на трех этапах исследования сравнивались между собой. Процедура проведения исследования с указанием этапов также представлена в таблице 2.

В исследовании фиксировались следующие физиологические параметры: частота сердечных сокращений (ЧСС); огибающая электромиограмма (ОЭМГ); с помощью фотоплетизмограммы измерялись амплитуда систолической волны (показатель объемного кровотока, АСВ) и время распространения пульсовой волны от сердца к периферии (ВРПВ). При значимом изменении как минимум двух из перечисленных показателей делался вывод о том, что испытуемый находился в физиологическом напряжении. ЧСС измерялась в количестве ударов в минуту с помощью электрокардиограммы (ЭКГ). Регистрация сердечного ритма происходила путем наложения датчиков на лучевые артерии рук с помощью электродов-клипсов. Также использовался нейтральный электрод. Помимо этого, для оценки физиологических показателей с помощью огибающей электромиограммы (ОЭМГ) регистрировались электрические сигналы, полученные в результате регистрации мышечных сокращений трапециевидной мышцы.

По итогам замеров физиологических параметров мы исключили из анализа данных результаты 7-ми человек (3-х курсантов и 4-х студентов) из первой и третьей групп, в которых проводилось стрессогенное воздействие, поскольку был сделан вывод об отсутствии у них физиологического напряжения. Все остальные участники в группах курсантов и студентов со стрессовым воздействием находились в состоянии физиологического напряжения, а в группах без стрессогенного воздействия все участники не демонстрировали напряжения.

\section{Измерение объема кратковременной памяти}

Предварительное и итоговое тестирование объема кратковременной памяти осуществлялись с помощью методики Digit Span Test посредством предъявления испытуемому рядов цифр, постепенно возрастающих по количеству знаков (Jones \& Macken, 2015). Для обследования в условиях стрессогенного воздействия и без него были сконструированы разные наборы рядов цифр. Пример стимульного материала представлен ниже (рис. 1).

Инструкция испытуемому давалась на экране монитора и включала следующее содержание: «Сейчас на экране вам будут предъявляться ряды случайных чисел, содержащих от 4 до 10 элементов, начиная с самого короткого. Когда экран станет зеленым, сразу же назовите вслух цифры в той же последовательности, в которой они были даны». 
БИТЮЦКАЯ Е. В., ЛЕБЕДЕВА Н. А., ЦАЛИКОВА Ю. Р.

ИЗМЕНЕНИЕ ОБЪЕМА КРАТКОВРЕМЕННОЙ ПАМЯТИ ПОД ВЛИЯНИЕМ СТРЕССОГЕННОГО ВОЗДЕЙСТВИЯ У КУРСАНТОВ РосСийский психологИчЕский жУРнАл, 2020, Т. 17, № 1, 27-43. doi: 10.21702/rpj.2020.1.3

ОБЩАЯ ПСИХОЛОГИЯ, ПСИХОЛОГИЯ ЛИЧНОСТИ, ИСТОРИЯ ПСИХОЛОГИИ

\begin{tabular}{|l|c|l|c|}
\hline $\begin{array}{c}\text { Предварительное тестирование } \\
\text { (1-я серия предъявлений } \\
\text { Digit Span Test) }\end{array}$ & \multicolumn{2}{|c|}{$\begin{array}{c}\text { Итоговое тестирование } \\
\text { (2-я серия предъявлений } \\
\text { Digit Span Test) }\end{array}$} \\
\hline 1. & 1-е предьявление & \multicolumn{2}{|c|}{ 1-е предьявление } \\
\hline 2. & 2587 & 1. & 1540 \\
\hline 3. & 98752 & 2. & 65742 \\
\hline 4. & 7541238 & 4. & 274918 \\
\hline 5. & 74125895 & 5. & 9546320 \\
\hline 6. & 105786428 & 6. & 45157621 \\
\hline 7. & 4582168732 & 7. & 7514682054 \\
\hline & $2-$ предьявление & & 2 -е предъявление \\
\hline 1. & 8542 & 1. & 4928 \\
\hline 2. & 75423 & 2. & 86547 \\
\hline 3. & 158634 & 3. & 105682 \\
\hline 4. & 2690267 & 4. & 4210856 \\
\hline 5. & 95486327 & 5. & 84751026 \\
\hline 6. & 791742250 & 6. & 359405482 \\
\hline 7. & 3521404861 & 7. & 1815497201 \\
\hline
\end{tabular}

Рисунок 1. Digit Span Test, который предьявлялся испытуемым

\section{Процедура обработки данных}

Объем кратковременной памяти вычислялся по формуле $\mathrm{V}=\mathrm{A}+\frac{\mathrm{m}}{\mathrm{n}}$, где $\mathrm{V}$ обозначает объем кратковременной памяти; А - наибольшую длину ряда, который был правильно воспроизведен во всех предъявлениях; m - количество правильно воспроизведенных цифровых рядов, больше A; n - число серий (в нашем случае - 2). При обработке результатов Digit Span Test учитывались только те цифровые ряды, которые были воспроизведены полностью и в верном порядке.

Полученные данные обрабатывались с помощью программы «IBM SPSS Statistics» Version 22. Были использованы следующие показатели: критерий Краскела-Уоллиса для независимых выборок, критерий Уилкоксона для связанных выборок, критерий Манна-Уитни для двух независимых выборок, коэффициент Спирмена, показатель оценки величины эффекта d-Коэна. При этом размер эффекта определялся как $\mathrm{d}=0,2-$ малый эффект; $\mathrm{d}=0,5$ - средний; $\mathrm{d}=$ 0,8 большой эффект (Cohen, 1988).

\section{Результаты}

В первой серии Digit Span Test, которая проходила в нейтральных условиях, для 4-х групп сравнения получены сопоставимые результаты (статистика критерия Краскелла-Уоллиса: $\mathrm{H}=3,374 ; \mathrm{p}=0,337$ ). 
БИТЮЦКАЯ Е. В., ЛЕБЕДЕВА Н. А., ЦАЛИКОВА Ю. Р.

ИЗМЕНЕНИЕ ОБЪЕМА КРАТКОВРЕМЕННОЙ ПАМЯТИ ПОД ВЛИЯНИЕМ СТРЕССОГЕННОГО ВОЗДЕЙСТВИЯ У КУРСАНТОВ

РосСИЙСКИЙ пСИХОЛОГИЧЕСКИЙ ЖУРнАл, 2020, Т. 17, № 1, 27-43. doi: 10.21702/rpj.2020.1.3

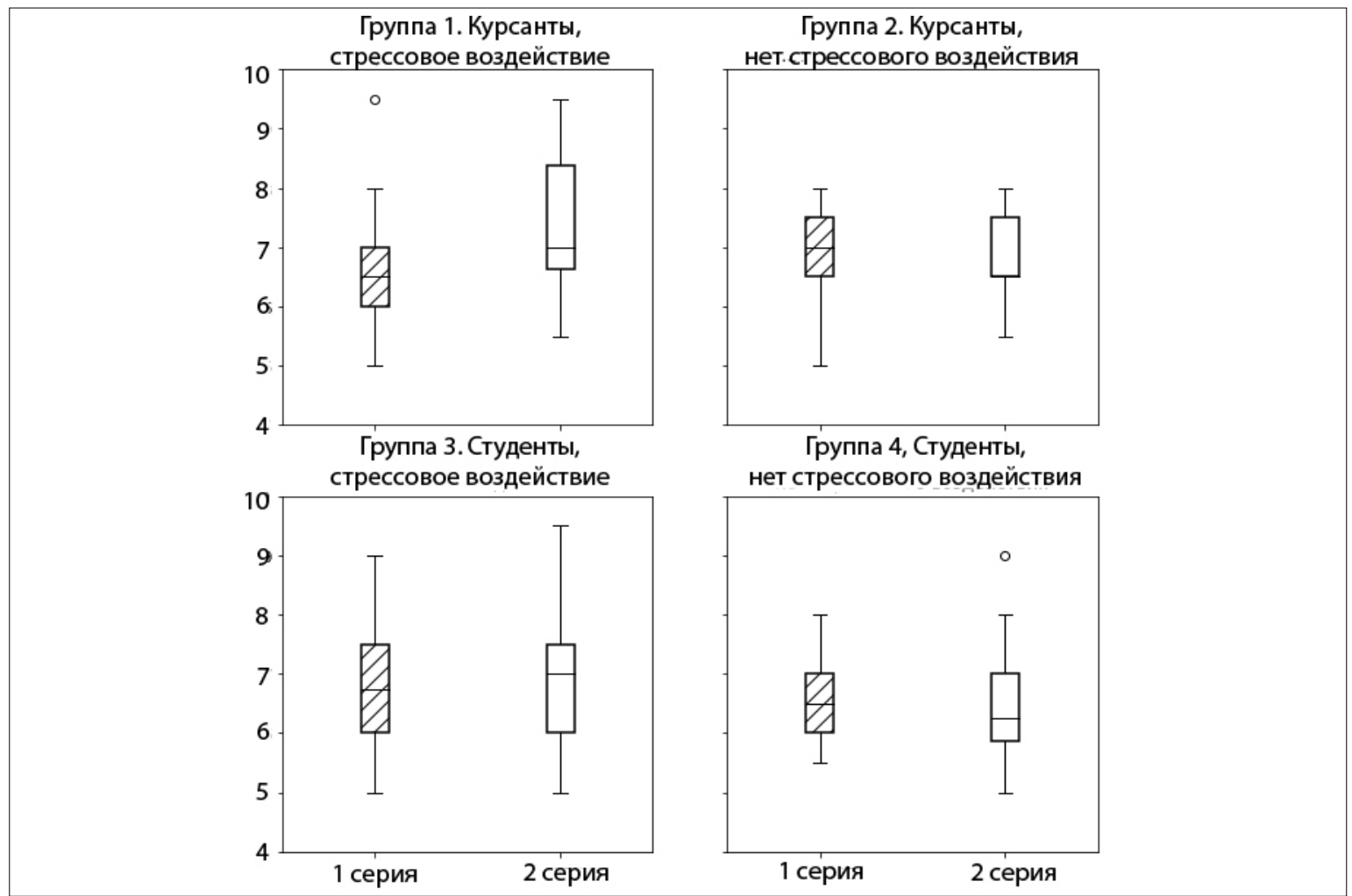

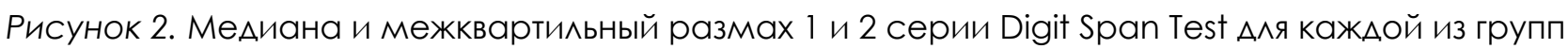

По вертикали: объем кратковременной памяти. По горизонтали: результаты 1-й и 2-й cepuй Digit Span Test.

Результаты диагностики по Digit Span Test представлены в таблице 3 и рисунке 2, где для сравнения приведены показатели первой и второй серий тестирования каждой группы участников исследования. При обращении к данным второй серии видно, что курсанты, выполняющие Digit Span Test в условиях стрессогенного воздействия, показывают более высокие результаты (показатель статистики по Критерию Уилкоксона $p=0,001$ ). Согласно показателю $\mathrm{d}$-Коэна, размер полученного эффекта средний $(\mathrm{d}=0,7232)$. Этот результат не может быть объяснен эффектом научения: курсанты, также выполняющие Digit Span Test второй раз, но без условий стрессогенной стимуляции, результаты в среднем не улучшили.

У студентов обеих групп (со стрессогенным воздействием и без него), а также курсантов второй группы (без стрессогенного воздействия) наблюдается незначимое снижение результатов по методике на запоминание. Отличий между результатами девушек и юношей выявлено не было.

В таблице 4 представлены обобщенные по количеству испытуемых данные о том, как менялся объем кратковременной памяти во второй серии исследования, по сравнению с первой серией, внутри каждой из исследуемых групп. Отметим, что в экспериментальной группе курсантов, выполняющих вторую серию Digit Span Test в условиях стрессогенного воздействия (группа 1), 66,7\% человек улучшили свои результаты; $20 \%$ ухудшили; у 13,3\% показатели не изменились. У курсантов группы 2 (без стрессогенного воздействия) увеличение 
БИТЮЦКАЯ Е. В., ЛЕБЕДЕВА Н. А., ЦАЛИКОВА Ю. Р.

ИЗМЕНЕНИЕ ОБЪЕМА КРАТКОВРЕМЕННОЙ ПАМЯТИ ПОД ВЛИЯНИЕМ СТРЕССОГЕННОГО ВОЗДЕЙСТВИЯ У КУРСАНТОВ

Российский психологИчЕский жУРнАл, 2020, Т. 17, № 1, 27-43. doi: 10.21702/rpj.2020.1.3

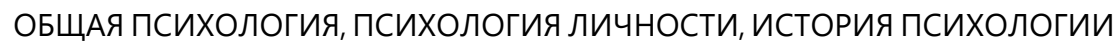

показателей объема кратковременной памяти обнаружено у $25 \%$, уменьшение - у $35 \%$; у $40 \%$ испытуемых объем кратковременной памяти не изменился.

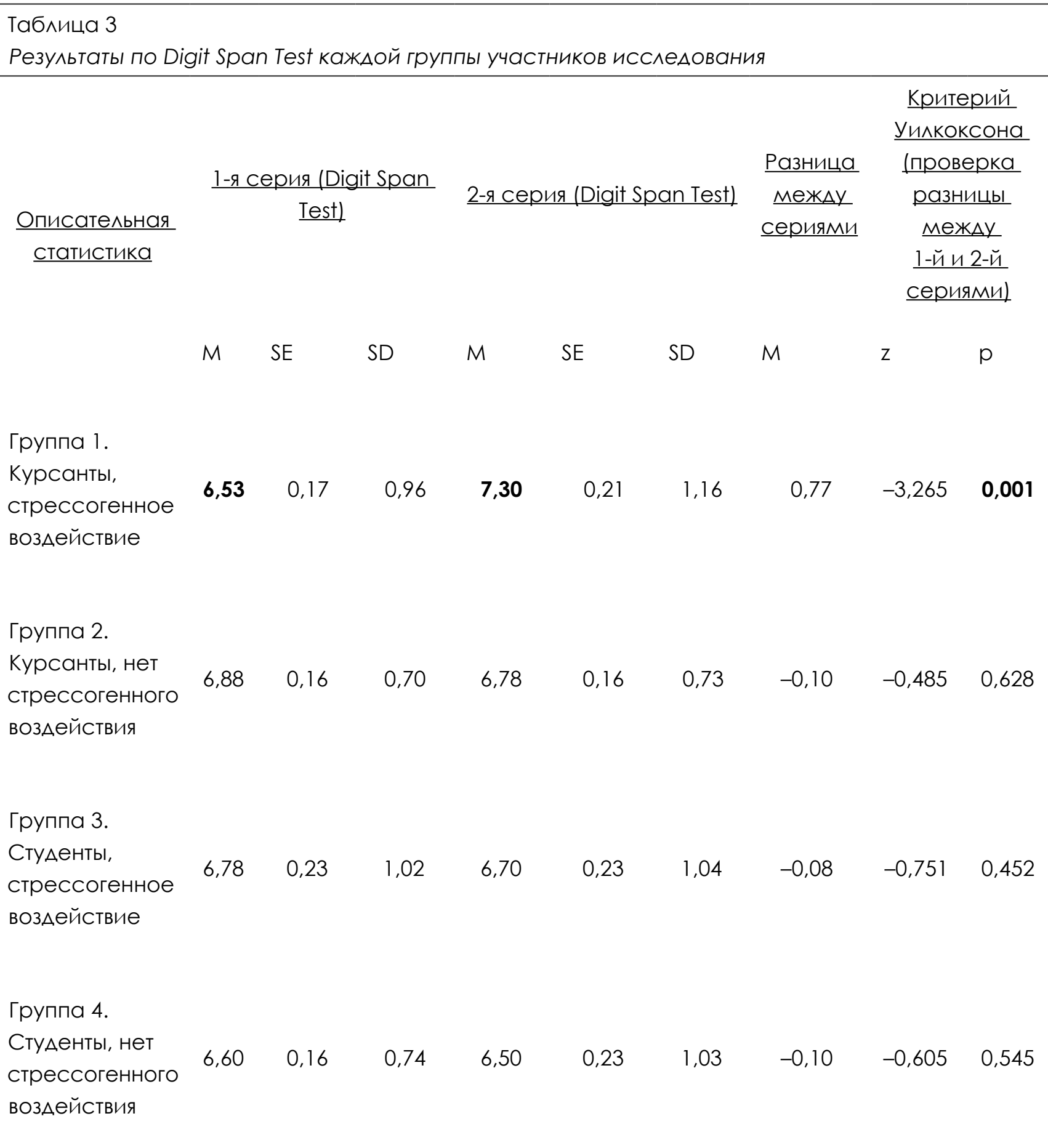


БИТЮЦКАЯ Е. В., ЛЕБЕДЕВА Н. А., ЦАЛИКОВА Ю. Р.

ИЗМЕНЕНИЕ ОБЪЕМА КРАТКОВРЕМЕННОЙ ПАМЯТИ ПОД ВЛИЯНИЕМ СТРЕССОГЕННОГО ВОЗДЕЙСТВИЯ У КУРСАНТОВ

РосСИЙСКИЙ пСИХОЛОГИЧЕСКИЙ ЖУРнАл, 2020, Т. 17, № 1, 27-43. doi: 10.21702/rpj.2020.1.3

ОБЩАЯ ПСИХОЛОГИЯ, ПСИХОЛОГИЯ ЛИЧНОСТИ, ИСТОРИЯ ПСИХОЛОГИИ

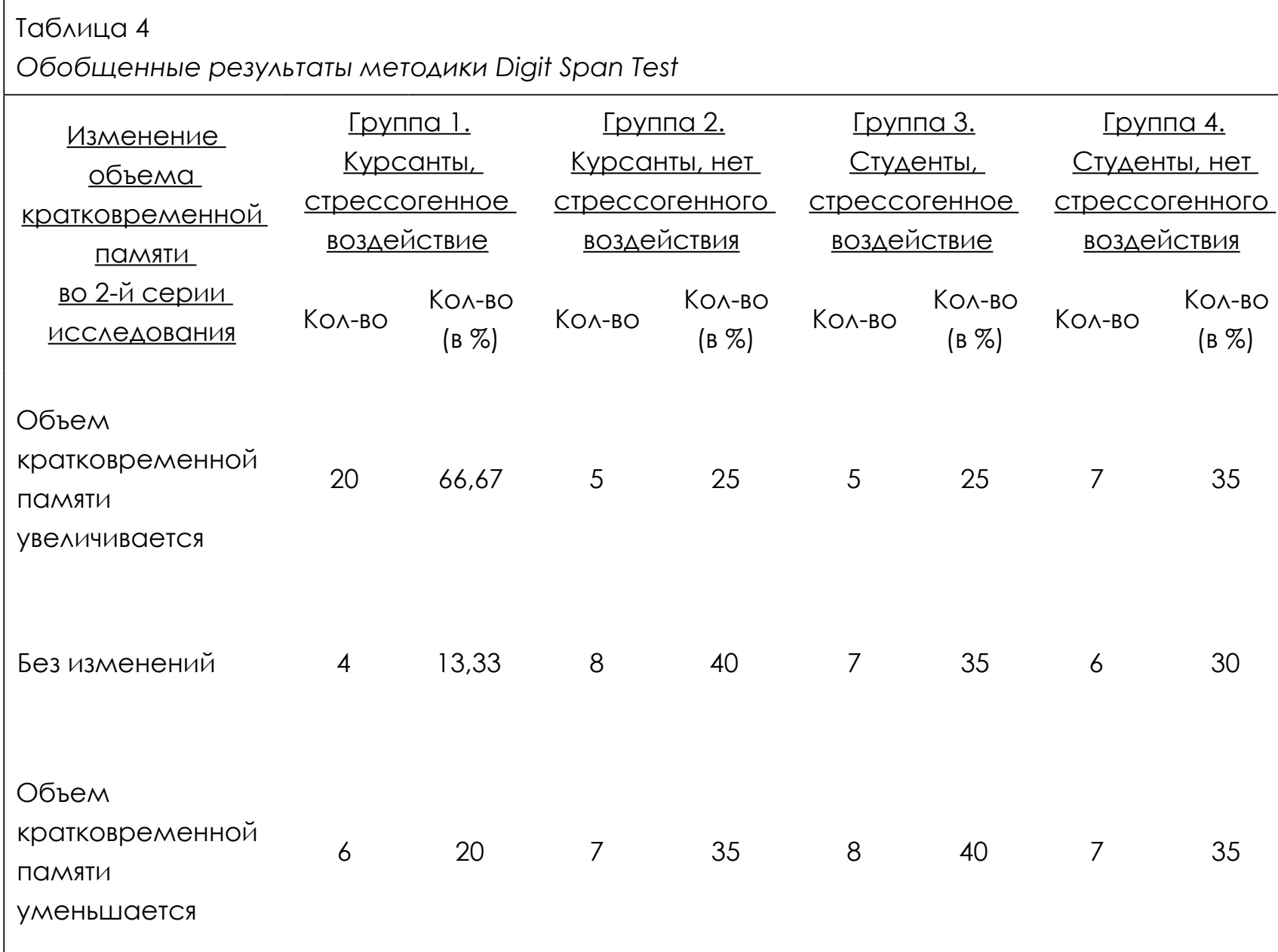

В группе 3 (студенты, подвергавшиеся воздействию стрессогенных стимулов) увеличение объема кратковременной памяти показали $25 \%$ испытуемых, уменьшение - 40 \%; у 35 \% участников объем не изменился. В группе 4 (студенты, не находившиеся в условиях стрессогенного воздействия) во второй серии исследования одинаковое количество (35\%) участников показали уменьшение и увеличение объема памяти, у 30 \% показатели не изменились.

В таблицах 5 и 6 представлены физиологические показатели 3-х этапов эксперимента двух групп испытуемых, подвергавшихся стрессогенному воздействию. У студентов отмечалось более высокое исходное мышечное напряжение, чем у курсантов ( $z=-1,99 ; p=0,047$; d-Коэна = 0,669), при выполнении первой серии Digit Span Test показатели амплитуды систолической волны (объем кровотока мелких сосудов) $(z=-2,222 ; p=0,026 ; d-$ Коэна = 1,41) и время распространения пульсовой волны у курсантов были ниже $(z=-2,743 ; p=0,006$; $\mathrm{d}$-Коэна = 0,665); во второй серии Digit Span Test скорость распространения пульсовой волны у курсантов также была ниже, чем у студентов ( $z=-2,278 ; p=0,023 ; d-$ Коэна = 0,6605). При этом, если проанализировать разницу между состоянием в нейтральных и стрессогенных условиях, показатели АСВ студентов изменились больше $(z=-2,131 ; p=0,033)$. 
БИТЮЦКАЯ Е. В., ЛЕБЕДЕВА Н. А., ЦАЛИКОВА Ю. Р.

ИЗМЕНЕНИЕ ОБЪЕМА КРАТКОВРЕМЕННОЙ ПАМЯТИ ПОД ВЛИЯНИЕМ СТРЕССОГЕННОГО ВОЗДЕЙСТВИЯ У КУРСАНТОВ

РОССиЙСКИЙ пСИХОЛОГИЧЕскИй ЖУРнАл, 2020, Т. 17, № 1, 27-43. doi: 10.21702/rpj.2020.1.3

ОБЩАЯ ПСИХОЛОГИЯ, ПСИХОЛОГИЯ ЛИЧНОСТИ, ИСТОРИЯ ПСИХОЛОГИИ

\begin{tabular}{|c|c|c|c|c|c|c|c|c|c|c|c|c|}
\hline \multicolumn{13}{|c|}{$\begin{array}{l}\text { Таблица } 5 \\
\text { Физиологические показатели курсантов и студентов в } \\
\text { (группа } 1 \text { и группа 3) на разных этапах исследования }\end{array}$} \\
\hline \multirow{3}{*}{ Этапы } & \multicolumn{3}{|c|}{$\frac{\text { ЭКГ - } 1 ; \text { ЧCC (YА. }}{\text { МИН.) }}$} & \multicolumn{3}{|c|}{$\frac{\text { Палец L; ACB }}{(\mathrm{pm})}$} & \multicolumn{3}{|c|}{ Палец L; ВРПВ (МС) } & \multicolumn{3}{|c|}{$\Pi M ; О Э М Г(M K B)$} \\
\hline & \multirow{2}{*}{ M } & \multicolumn{2}{|c|}{$M \pm S D$} & \multirow{2}{*}{ M } & \multicolumn{2}{|c|}{$M \pm S D$} & \multirow{2}{*}{ M } & \multicolumn{2}{|c|}{$M \pm S D$} & \multirow{2}{*}{ M } & \multicolumn{2}{|c|}{$M \pm S D$} \\
\hline & & $\mathrm{H} \Gamma$ & $\mathrm{B} \Gamma$ & & $\mathrm{HГ}$ & $\mathrm{B} \Gamma$ & & $\mathrm{H} \Gamma$ & $\mathrm{B} \Gamma$ & & $\mathrm{HГ}$ & $\mathrm{B} \Gamma$ \\
\hline $\begin{array}{l}\text { Исхол- } \\
\text { ный орон, } \\
\text { курсанты }\end{array}$ & 88,57 & 66,40 & 110,73 & 0,53 & 0,31 & 0,75 & 185,04 & 151,68 & 218,40 & 7,84 & 4,24 & 10,44 \\
\hline $\begin{array}{l}\text { Исхол- } \\
\text { ный орон, } \\
\text { студенты }\end{array}$ & 86,05 & 72,42 & 100,67 & 1,06 & 0,56 & 1,56 & 198,75 & 172,97 & 224,54 & 11,10 & 8,26 & 13,89 \\
\hline $\begin{array}{l}\text { Выпол- } \\
\text { нение } \\
\text { Digit } \\
\text { Span Test, } \\
\text { нейт- } \\
\text { ральные } \\
\text { условия, } \\
\text { курсанты }\end{array}$ & 88,15 & 78,29 & 98,01 & 0,53 & 0,42 & 0,64 & 181,13 & 165,45 & 196,81 & 7,95 & 5,10 & 10,14 \\
\hline $\begin{array}{l}\text { Выпол- } \\
\text { нение } \\
\text { Digit } \\
\text { Span Test, } \\
\text { нейт- } \\
\text { ральные } \\
\text { условия, } \\
\text { студенты }\end{array}$ & 91,07 & 81,48 & 99,17 & 1,29 & 0,75 & 1,83 & 197,24 & 167,99 & 226,50 & 10,51 & 8,21 & 12,82 \\
\hline
\end{tabular}


БИТЮЦКАЯ Е. В., ЛЕБЕДЕВА Н. А., ЦАЛИКОВА Ю. Р.

ИЗМЕНЕНИЕ ОБЪЕМА КРАТКОВРЕМЕННОЙ ПАМЯТИ ПОД ВЛИЯНИЕМ СТРЕССОГЕННОГО ВОЗДЕЙСТВИЯ У КУРСАНТОВ

РОССИЙСКИЙ ПСИХОЛОГИЧЕСКИЙ ЖУРнАЛ, 2020, Т. 17, № 1, 27-43. doi: 10.21702/rpj.2020.1.3

ОБЩАЯ ПСИХОЛОГИЯ, ПСИХОЛОГИЯ ЛИЧНОСТИ, ИСТОРИЯ ПСИХОЛОГИИ

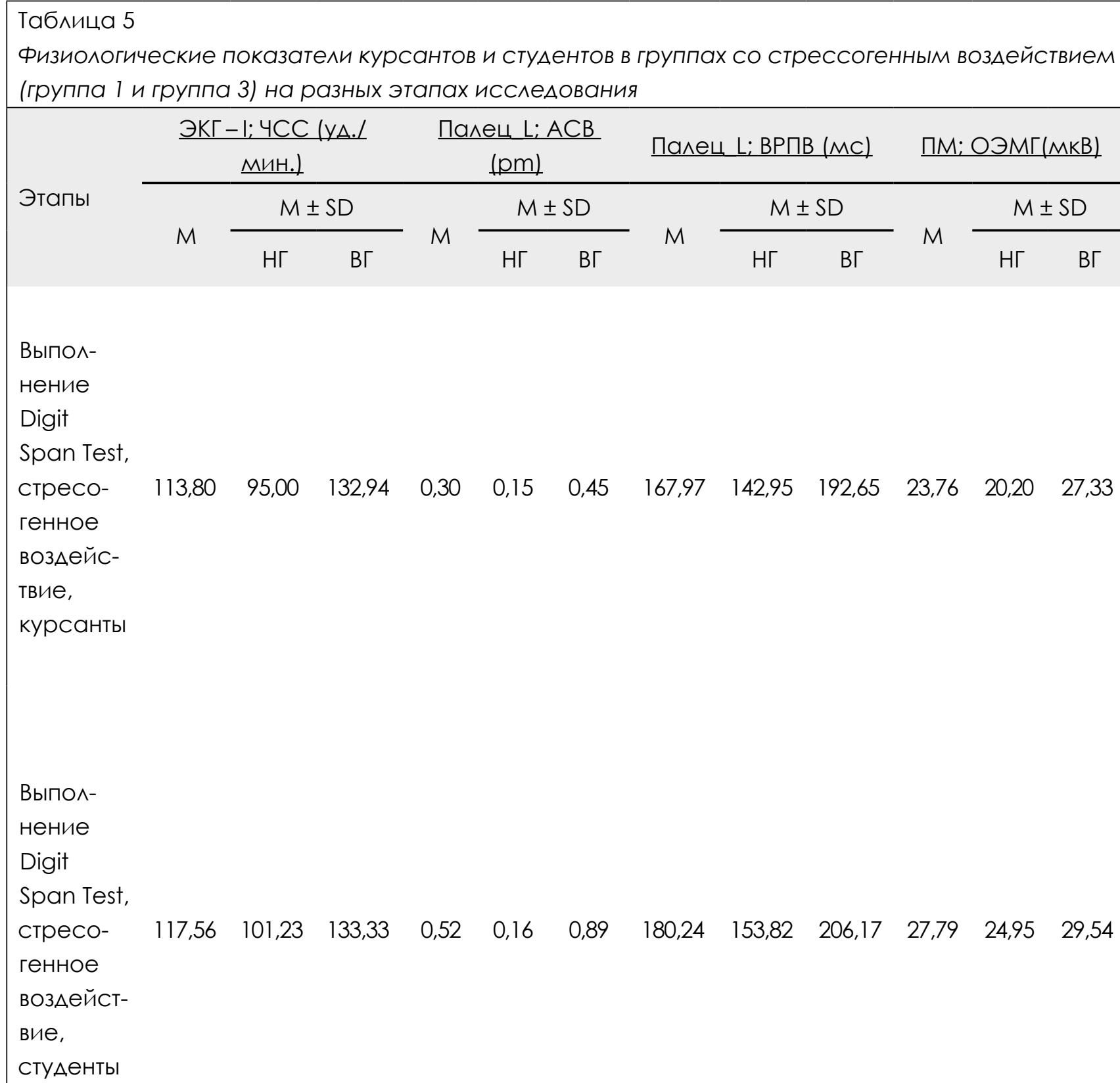

Примечание: ЭКГ - электрокарлиограмма: ЧСС - частота серлечных сокращений; АСВ - амплитуда систолической волны; ВРПВ - время распространения пульсовой волны; ОЭМГ - огибающая электромиограмма; М - среднее; SD - среднеквалратичное отклонение; НГ - нижняя граница; ВГ-верхняя граница. 
БИТЮЦКАЯ Е. В., ЛЕБЕДЕВА Н. А., ЦАЛИКОВА Ю. Р.

ИЗМЕНЕНИЕ ОБЪЕМА КРАТКОВРЕМЕННОЙ ПАМЯТИ ПОД ВЛИЯНИЕМ СТРЕССОГЕННОГО ВОЗДЕЙСТВИЯ У КУРСАНТОВ

Российский психологИчЕский жУРнАл, 2020, Т. 17, № 1, 27-43. doi: 10.21702/rpj.2020.1.3

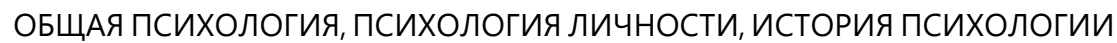

\begin{tabular}{|c|c|c|c|c|c|}
\hline $\begin{array}{l}\text { Таблица } 6 \\
\text { Разница фризиоло } \\
\text { воздействием }\end{array}$ & гических пс & азателей к & Сантов И С & ентов в & ппах со стрессогенным \\
\hline & Курсанты & Студенты & $\begin{array}{l}\text { U Манна- } \\
\text { Уитни }\end{array}$ & Z & $\begin{array}{c}\text { Асимптотическая значи- } \\
\text { мость (2-сторонняя) }\end{array}$ \\
\hline Аельта 1 ЧСС, & $-0,41$ & 5,03 & 191,000 & $-2,159$ & 0,031 \\
\hline 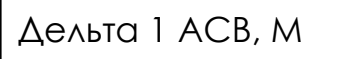 & 0,00 & 0,23 & 227,500 & $-1,438$ & 0,151 \\
\hline$\triangle$ елььта 1 ВРПВ, M & $-3,91$ & $-1,51$ & 249,000 & $-1,010$ & 0,313 \\
\hline Аельта 1 ОЭМГ, М & 0,12 & $-0,59$ & 254,500 & $-0,901$ & 0,368 \\
\hline Аельта 2 ЧСС, & 25,65 & 26,48 & 296,000 & $-0,079$ & 0,937 \\
\hline Аельта 2 ACB, M & $-0,23$ & $-0,77$ & 192,500 & $-2,131$ & 0,033 \\
\hline$\triangle$ Аельта 2 ВРПВ, M & $-13,16$ & $-17,00$ & 300,000 & 0,000 & 1,000 \\
\hline Аельта 2 ОЭМГ, М & 15,81 & 17,28 & 269,000 & $-0,614$ & 0,539 \\
\hline
\end{tabular}

\section{Обсуждение результатов}

Гипотеза данного исследования частично подтвердилась: у 67 \% курсантов объем памяти в условиях стрессогенного воздействия увеличился, по сравнению с объемом памяти в нейтральных условиях. Таким образом, мы получили результаты, которые показывают, что под воздействием стрессогенных факторов большинство курсантов способны увеличивать показатели когнитивной активности. Это согласуется с исследованиями обратной U-образной зависимости физиологического напряжения и продуктивности, в которых показано, что стрессогенное воздействие умеренной интенсивности оказывает мобилизующий эффект (Easterbrook, 1959; McGaugh, 2006; Hancock \& Weaver, 2005). При этом нам видится важным ответить на вопрос о том, что привело к разным результатам в группах у курсантов и студентов. Существует несколько возможных объяснений:

1. Можно предположить, что две группы находились на разных уровнях обратной U-образной зависимости. Возможно, для курсантов этот уровень воздействия был умеренный, приводил к меньшему физиологическому ответу и улучшению запоминания, тогда как для студентов 
БИТЮЦКАЯ Е. В., ЛЕБЕДЕВА Н. А., ЦАЛИКОВА Ю. Р.

ИЗМЕНЕНИЕ ОБЪЕМА КРАТКОВРЕМЕННОЙ ПАМЯТИ ПОД ВЛИЯНИЕМ СТРЕССОГЕННОГО ВОЗДЕЙСТВИЯ У КУРСАНТОВ

РосСИЙСКИЙ пСИХОЛОГИЧЕСКИЙ ЖУРнАл, 2020, Т. 17, № 1, 27-43. doi: 10.21702/rpj.2020.1.3

ОБЩАЯ ПСИХОЛОГИЯ, ПСИХОЛОГИЯ ЛИЧНОСТИ, ИСТОРИЯ ПСИХОЛОГИИ

данное воздействие было более сильным, при этом, однако, не вызывая ухудшения запоминания. Как видно из таблицы 5, физиологический ответ курсантов и студентов отличался; эта разница требует более детального рассмотрения. Так, данные показывают, что мобилизация курсантов произошла уже во время выполнения 1-й серии Digit Span Test, поэтому изменение кровотока в мелких сосудах во время 2-й серии было не таким выраженным, как у студентов.

2. Существует разница в мотивационно-эмоциональной регуляции возникшего физиологического состояния. Курсанты способны сохранять высокую продуктивность познавательных процессов в стрессогенных условиях. Это связано на мотивационном уровне - с целенаправленностью действий, с высокой ценностью помощи людям, спасения жизней; на уровне профессионально важных психологических качеств - с оптимистичностью, позитивной оценкой своих сил и возможностей, энергичностью (которые являются составляющими оценки «вызов»). Кроме того, курсанты отобраны для решения таких задач при помощи медицинского и психологического отбора. Также они обучаются и тренируются сохранять самообладание и устойчивость при выполнении двигательных и когнитивных задач в сложных условиях (Битюцкая, Елисеева и Шойгу, 2015). Таким образом, возможно, в условиях стрессогенного воздействия курсанты, в отличие от студентов, в большей степени направлены на активное разрешение внешней задачи (Гуренкова и др., 2007).

Наряду с тем, что для большинства курсантов зафиксировано увеличение объема кратковременной памяти, у 20 \% курсантов показатели ухудшились, у $13 \%$ не изменились. Для объяснения этого факта было проведено дополнительное исследование. При этом мы опирались на работы о саморегуляции, в которых функции кратковременной памяти рассматривались в соотношении с интеллектом и мышлением (Barrett et al., 2004; Величковский, 2016). Были проанализированы корреляции уровня невербального интеллекта курсантов по методике «Прогрессивные матрицы Равена» и показателей 2-й серии Digit Span Test. Коэффициент корреляции Спирмена составил 0,585 ( ровали увеличение объема кратковременной памяти в стрессовой ситуации, на $5 \%$ состояла из людей со средним уровнем интеллекта, на 55 \% с уровнем «выше среднего», и на $40 \%$ из людей с высоким уровнем интеллекта. Среди тех курсантов, которые показали снижение и сохранение объема кратковременной памяти, большинство (60\%) имели средний уровень развития интеллекта, у $30 \%$ наблюдался уровень интеллекта ниже среднего, и у $10 \%$-высокий. Этот анализ свидетельствует в пользу того, что эффективность саморегуляции в стрессовой ситуации может быть рассмотрена как в связи с функционированием кратковременной памяти, так и с интеллектуальными показателями.

\section{Заключение}

Результаты проведенного исследования об изменении объема кратковременной памяти в условиях стрессогенного воздействия показывают, что у $67 \%$ курсантов объем кратковременной памяти улучшился, у $20 \%$ курсантов показатели памяти ухудшились, у $13 \%$ - не изменились. Кроме того, курсанты показали более высокие результаты по сравнению с контрольной группой студентов.

При проведении дальнейших исследований важно учитывать, что для более точной диагностики выраженности физиологического состояния испытуемых, находящихся в условиях стрессогенного воздействия, необходимо применение дополнительных методов, например, анализа кортизола слюны. 
БИТЮЦКАЯ Е. В., ЛЕБЕДЕВА Н. А., ЦАЛИКОВА Ю. Р.

ИЗМЕНЕНИЕ ОБЪЕМА КРАТКОВРЕМЕННОЙ ПАМЯТИ ПОД ВЛИЯНИЕМ СТРЕССОГЕННОГО ВОЗДЕЙСТВИЯ У КУРСАНТОВ

Российский психологИчЕский жУРнАл, 2020, Т. 17, № 1, 27-43. doi: 10.21702/rpj.2020.1.3

ОБЩАЯ ПСИХОЛОГИЯ, ПСИХОЛОГИЯ ЛИЧНОСТИ, ИстОРИЯ ПСИхОЛОГИИ

\section{Литература}

Битюцкая, Е. В., Елисеева, И. Н. и Шойгу, Ю. С. (2015). К вопросу о психологических механизмах подготовки спасателей к профессиональной деятельности. В В. Т. Кудрявцев (ред.), Обучение и развитие: современная теория и практика: Материалы XVI Международных чтений памяти Л. С. Выготского. Москва, 16-20 ноября 2015 г.: В 2 ч. Ч. 1 (с. 240-244). Москва: Левъ.

Бодров, В. А. и Обознов, А. А. (2000). Система психической регуляции стрессоустойчивости человека-оператора. Психологический журнал, 21(4), 32-40.

Величковский, Б. Б. (2016). Влияние рабочей памяти на эффективность саморегуляции поведения и копинга. В Т. Л. Крюкова, М. В. Сапоровская, С. А. Хазова (отв. ред.), Психология стресса и совладающего поведения: ресурсы, здоровье, развитие: материалы IV Междунар. науч. конФ. Кострома, 22-24 сент. 2016 г.: в 2 m. (с. 25-27). Кострома: КГУ им. Н. А. Некрасова.

Гуренкова, Т. Н., Елисеева, И. Н., Кузнецова, Т. Ю., Макарова, О. Л., Матафонова, Т. Ю., Павлова, М. В. и Шойгу, Ю. С. (2007). В Ю. С. Шойгу (общ. ред.), Психология экстремальных ситуаций для спасателей и пожарных. Москва: Смысл.

Дикая, Л. Г. (1999). Системно-деятельностная концепция саморегуляции психофизиологического состояния человека. В Л. Г. Дикая (отв. ред.), Проблемность в профессиональной деятельности: теория и методы психологического анализа (с. 80-106). Москва: Институт психологии РАН.

Дикая, Л. Г. и Щедров, В. И. (1999). Метод определения индивидуального стиля саморегуляции психического состояния человека. В Л. Г. Дикая (отв. ред.), Проблемность в профессиональной деятельности: теория и методы психологического анализа (с. 106-132). Москва: Институт психологии РАН.

Зотов, М. В. (2011). Механизмы регуляции познавательной деятельности в условиях эмоционального стресса. Санкт-Петербург: Речь.

Леонова, А. Б. и Кузнецова, А. С. (2015). Функциональные состояния и работоспособность человека в профессиональной деятельности. В Е. А. Климов, О. Г. Носкова, Г. Н. Солнцева (ред.), Психология труда, инженерная психология и эргономика (с. 319-346). Москва: Юрайт.

Шапкин, С. А. (1999). Методика изучения стратегий адаптации человека к стрессогенным условиям профессиональной деятельности. Метод определения индивидуального стиля саморегуляции психического состояния человека. В Л. Г. Дикая (отв. ред.), Проблемность в профессиональной деятельности: теория и методы психологического анализа (с. 132165). Москва: Институт психологии РАН.

Bargh, J. A., \& Cohen, J. L. (1978). Mediating factors in the arousal-performance relationship. Motivation and Emotion, 2, 243-257. doi: 10.1007/BF00992589

Barrett, L. F., Tugade, M. M., \& Engle, R. W. (2004). Individual differences in working memory capacity and dual-process theories of the mind. Psychological Bulletin, 130(4), 553-573. doi: 10.1037/0033-2909.130.4.553

Blascovich, J., \& Tomaka, J. (1996). The biopsychosocial model of arousal regulation. Advances in Experimental Social Psychology, 28, 1-51. doi: 10.1016/S0065-2601(08)60235-X

Bonanno, G. A., Papa, A., Lalande, K., Westphal, M., \& Coifman, K. (2004). The importance of being flexible: The ability to both enhance and suppress emotional expression predicts long-term adjustment. Psychological Science, 15(7), 482-487. doi: 10.1111/j.0956-7976.2004.00705.x

Buchanan, T. W., \& Lovallo, W. R. (2001). Enhanced memory for emotional material following stress-level cortisol treatment in humans. Psychoneuroendocrinology, 26(3), 307-317. doi: $10.1016 / \mathrm{s} 0306-4530(00) 00058-5$ 
БИТЮЦКАЯ Е. В., ЛЕБЕДЕВА Н. А., ЦАЛИКОВА Ю. Р.

ИЗМЕНЕНИЕ ОБЪЕМА КРАТКОВРЕМЕННОЙ ПАМЯТИ ПОД ВЛИЯНИЕМ СТРЕССОГЕННОГО ВОЗДЕЙСТВИЯ У КУРСАНТОВ

РосСИЙСКИЙ пСИХОЛОГИЧЕСКИЙ ЖУРнАл, 2020, Т. 17, № 1, 27-43. doi: 10.21702/rpj.2020.1.3

ОБЩАЯ ПСИХОЛОГИЯ, ПСИХОЛОГИЯ ЛИЧНОСТИ, ИСТОРИЯ ПСИХОЛОГИИ

Buchanan, T. W., Tranel, D., \& Adolphs, R. (2006). Impaired memory retrieval correlates with individual differences in cortisol response but not autonomic response. Learning \& Memory, 13, 382-387. doi: 10.1101/lm.206306

Cahill, L, Gorski, L, \& Le, K. (2003). Enhanced human memory consolidation with post-learning stress: Interaction with the degree of arousal at encoding. Learning \& Memory, 10, 270-274. doi: $10.1101 / 1 \mathrm{~m} .62403$

Cohen, J. (1988). Statistical power analysis for the behavioral sciences (2nd ed.). Hillsdale, NJ: Lawrence Erlbaum Associates, Publishers.

Crum, A. J., Salovey, P., \& Achor, S. (2013). Rethinking stress: The role of mindsets in determining the stress response. Journal of Personality and Social Psychology, 104(4), 716-733. doi: 10.1037/a0031201

Easterbrook, J. A. (1959). The effect of emotion on cue utilization and the organization of behavior. Psychological Review, 66(3), 183-201. doi: 10.1037/h0047707

Hancock, P. A., \& Weaver, J. L. (2005). On time distortion under stress. Theoretical Issues in Ergonomics Science, 6(2), 193-211. doi: 10.1080/14639220512331325747

Hase, A., O'Brien, J., Moore, L. J., \& Freeman, P. (2019). The relationship between challenge and threat states and performance: A systematic review. Sport, Exercise, and Performance Psychology, 8(2), 123-144. doi: 10.1037/spy0000132

Jamieson, J. P., Mendes, W. B., Blackstock, E., \& Schmader, T. (2010). Turning the knots in your stomach into bows: Reappraising arousal improves performance on the GRE. Journal of Experimental Social Psychology, 46(1), 208-212. doi: 10.1016/j.jesp.2009.08.015

Jones, G., \& Macken, B. (2015). Questioning short-term memory and its measurement: Why digit span measures long-term associative learning. Cognition, 144, 1-13. doi: 10.1016/j.cognition.2015.07.009

Lazarus, R. S. (1991). Progress on a cognitive-motivational-relational theory of emotion. American Psychologist, 46(8), 819-834. doi: 10.1037/0003-066x.46.8.819

Levine, L. J., \& Burgess, S. L. (1997). Beyond general arousal: Effects of specific emotions on memory. Social Cognition, 15(3), 157-181. doi: 10.1521/soco.1997.15.3.157

Levine, L. J., \& Pizarro, D. A. (2004). Emotion and memory research: A grumpy overview. Social Cognition, 22(5), 530-554. doi: 10.1521/soco.22.5.530.50767

Mather, M. (2007). Emotional arousal and memory binding: An object-based framework. Perspectives on Psychological Science, 2(1), 33-52. doi: 10.1111/j.1745-6916.2007.00028.x

McGaugh, J. L. (2006). Make mild moments memorable: add a little arousal. Trends in Cognitive Sciences, 10(8), 345-347. doi: 10.1016/j.tics.2006.06.001

Sharot, T., \& Phelps, E. A. (2004). How arousal modulates memory: Disentangling the effects of attention and retention. Cognitive, Affective, \& Behavioral Neuroscience, 4, 294-306. doi: 10.3758/cabn.4.3.294

Tomaka, J., Blascovich, J., Kelsey, R. M., \& Leitten, C. L. (1993). Subjective, physiological, and behavioral effects of threat and challenge appraisal. Journal of Personality and Social Psychology, 65(2), 248-260. doi: 10.1037/0022-3514.65.2.248

Vine, S. J., Freeman, P., Moore, L. J., Chandra-Ramanan, R., \& Wilson, M. R. (2013). Evaluating stress as a challenge is associated with superior attentional control and motor skill performance: Testing the predictions of the biopsychosocial model of challenge and threat. Journal of Experimental Psychology: Applied, 19(3), 185-194. doi: 10.1037/a0034106

Vine, S. J., Uiga, L., Lavric, A., Moore, L. J., Tsaneva-Atanasova, K., \& Wilson, M. R. (2015). Individual reactions to stress predict performance during a critical aviation incident. Anxiety, Stress, \& Coping, 28(4), 467-477. doi: 10.1080/10615806.2014.986722

Конфликт интересов отсутствует 